Faculdade de Ciências Econômicas UFRGS
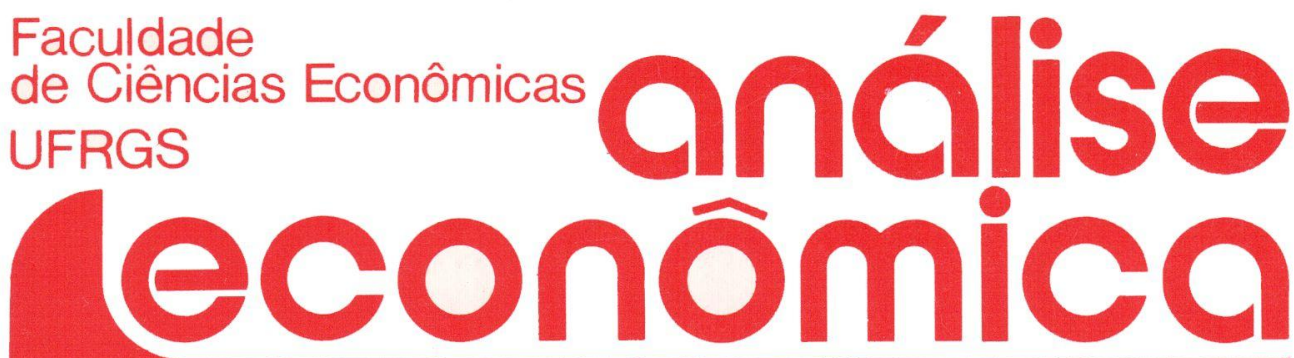

- A LINEAR MOdEL Of BALANCEd GROWTH Joanilio Rodolpho Teixeira Rodrigo Andrés de Souza Penaloza

- TEORIAS ESTRUTURALISTAS DA INFLAÇÃO

Roberto Camps Moraes

- PREÇOS EXTERNOS E EXPÓRTAÇÃO DE MANUFATURADOS Lauro Lobo Burle

- O DESENVOLVIMENTO SUECO Alfredo Marcolin Peringer

- DÉFICIT ENERGÉTICO Fabiano Augusto Nogueira Pinto

- RICARDO E O PROBLEMA SOCIAL Cezar Machado Mello

- UM SABER QUE NÃo SABE: INSTRUMENTO DE PREVISÃO Eleutério F.S. Prado

- SELEÇÃo dE PLANOS DE PRODUÇÃO PARA PEQUENOS PRODUTORES AGRICOLAS Juvir Luiz Mattuella

- PERSPECTIVAS da ECONOMIA do NORDESTE NA DÉCADA DE NOVENTA

Liana Maria da Frota Carleial

- CAIO PRADO JÚNIOR

Pedro Cezar Dutra Fonseca 
UNIVERSIDADE FEDERAL DO RIO GRANDE DO SUL Reitor. Prof. Tuiskon Dick

FACULDADE DE CIÊNCIAS ECONÔMICAS

Diretor: Prof. Walter Meucci Nique

CENTRO DE ESTUDOS E PESQUISAS ECONÔMICAS

Diretor: Reinaldo lgnácio Adams

DEPARTAMENTO DE CIÉNCIAS ECONÔMICAS

Chefe: Prof. Pedro Cezar Dutra Fonseca

CURSO DE PÓS-GRADUAÇÃO EM ECONOMIA

Coordenador: Prof. Nali de Jesus de Souza

CURSO DE PÓS-GRADUAÇĀO EM ECONOMIA RURAL

Coordenador. Prof. Atos Freitas Grawunder

CONSELHO EDITORIAL: Achyles Barcelos da Costa, Aray Miguel Feldens, Atos Freitas Grawunder, Carlos Augusto Crusius, Ernani Hickmann, João Rogério Sanson, Juvir Luiz Mattuella, Maria Imilda da Costa e Silva, Nali de Jesus de Souza, Nuno Renan Lopes de Figueiredo Pinto, Otília Beatriz Kroeff Carrion, Otto Guilherme Konzen, Paulo Alexandre Spohr, Pedro Cezar Dutra Fonseca, Reinaldo Ignacio Adams, Roberto Camps Moraes, Valter José Stülp, Yeda Rorato Crusius, David Garlow (Wharton Econometrics Forecasts Association, E.U.A.), Edgar Augusto Lanzer (UFSC), Eleutério F.S. Prado (USP), Fernando Holanda Barbosa (FGV/RJ), Gustavo Franco (PUC/RJ), Joaquim Pinto de Andrade (UnB), Juan H. Moldau (USP), Werner Baer (Univ. de Illinois, E.U.A.).

COMISSĀO EDITORIAL: Atos Freitas Grawunder, Pedro Cezar Dutra Fonseca, Reinaldo Ignacio Adams e Roberto Camps Moraes.

EDITOR: Nali de Jesus de Souza

SECRETARIA: Maria Ivone de Mello (normalização), Vanete Ricacheski (revisão de textos), Zélide Bregalda (Secretária).

FUNDADOR: Prof. Antônio Carlos Santos Rosa

Os materiais publicados na revista Análise Econômica são de exclusiva responsabilidade dos autores. É permitida a reprodução total ou parcial dos trabalhos, desde que seja citada a fonte.

Aceita-se permuta com revistas congêneres. Aceitam-se, também, livros para divulgação, elaboração de resenhas ou recensōes.

Toda correspondência, material para publicação, assinaturas e permutas devem ser dirigidos ao seguinte destinatário:

PROF. NALI DE JESUS DE SOUZA

Revista Análise Econômica

Av. João Pessoa, 52

90.040 - PORTO ALEGRE (RS), BRASIL

Telefone: (0512) 25-58-44 ramal 33

Fax: (0512) 25-5253 


\title{
RICARDO E O PROBLEMA SOCIAL DE SEU TEMPO*
}

\author{
Cézar Machado Mello**
}

\section{SINOPSE}

No modelo de Ricardo os salários são determinados pelo nivel de subsistência da classe trabalhadora. Sendo o cereal o principal produto de consumo dos trabalhadores, os salários monetários dependiam de seu preço. Como o crescimento demográfico deteriorava ainda mais o nivel de vida das classes trabalhadoras, havia muita tensão social na época de Ricardo. Para ele, a "Lei dos Pobres" agravava a situação ao estimular o crescimento demográfico.

\section{INTRODUÇÃO}

A convergência dos salários em nivel de subsistência, pelo mecanismo populacional, não consistia apenas em postulados teóricos dos livros de Ricardo e Malthus, mas fazia parte de uma dramática realidade vivida pela Inglaterra na virada do século XVIII. Como reflexo do estado de tensão social vigente, o parlamento inglês se detinha em intermináveis debates sobre as formas de lidar com os programas de assistência ao trabalhador. Infelizmente, as diversas tentativas de elevar o salário real dos trabalhadores viam-se sempre frustradas, seja pela elevação incontrolada do preço do cereal, seja pela impossibilidade de conciliar os salários com as condições de mercado.

Oportunamente, surgiu o modelo de Ricardo, esclarecendo o problema: os salários são sempre dados pelo nível mínimo de subsistência

* David Ricardo nasceu em Londres, em 1772, e faleceu em Gloucester, em 1823.

** Mestre em Economia pela UFRGS.

\begin{tabular}{|l|l|l|l|l|}
\hline ANÁLISE ECONO̊MICA & ANO 8 & № 14 & NOVEMBRO/90 & p.97-103 \\
\hline
\end{tabular}


da classe trabalhadora, também denominado nível natural, e, como o principal produto de consumo dos trabalhadores é o cereal, os salários monetários sempre variarão com o preço do cereal, resultando então na redundância de quaisquer intervenções nos parâmetros do mercado por vias legais.

\section{A QUESTÃO SOCIAL}

O quadro apresentado por Ricardo do trabalhador vivendo em nivel de subsistência não é exagerado, pelo menos no tocante aos menos qualificados. Tão vagarosos estavam os salários para acompanhar o preço do cereal que, em 1975, Whitbread (Apud Lecky, s.d., p.230) apresentou proposta ao Parlamento, com o objetivo de levar os empregadores a elevarem os salários, sempre que o cereal subisse. As condições do trabalhador agricola, que haviam chegado a ser razoáveis, tinham se deteriorado à miséria, pois os salários haviam permanecido os mesmos desde o início do século, ou seja, um shilling ou dezoito pence por dia, enquanto o preço do trigo subira de vinte e dois shillings o quarter para oitenta shillings ou mais.

A proposta de Whitbread foi rejeitada pelo Parlamento. Mesmo assim, sentia-se que algo devia ser feito e se pretendia evitar a fome generalizada. Então, as autoridades locais, responsáveis pelo alívio dos pobres, resolveram lidar com o assunto à sua maneira; passou-se a utilizar um velho ato dos tempos da rainha Elizabeth, pelo qual os juizes tinham o poder de delimitar a taxa de salários em cada distrito. A situação é descrita como se segue:

Em maio de 1795, um entre os magistrados de Berkshire foi mantido em Speenhamland ... quando então ficou unanimemente acertado que a situação dos pobres necessitava de uma melhor assistência do que a dada atế o momento. O encontro também decidiu dar o auxllio através da regulação dos salários segundo os estatutos Elizabetanos, mas que os magistrados deveriam encorajar os agricultores a aumentarem os salários de acordo com o preço das provisões. Eles então elaboraram uma escala, na qual se convertia o que deveriam ser os salários dos trabalhadores, de acordo com as elevações e quedas no preço do pão (...). Assim, quando o pão chegasse a custar meio shilling, o trabalhador deveria receber, seja através de seu próprio salário ou dos fundos dos pobres, três shillings para si e um shilling e seis pence para cada membro de sua famflia, e com o aumento de cada pence no pão, ele deveria receber um adicional de três 
pence, para si e um pence para cada membro da famflia (Harold, 1947, p.408).

Esta decisão da justiça de Berkshire não obrigava os outros condados a segui-la, mas o seu efeito foi tão marcante que logo a maior parte deles voluntariamente a estavam adotando. Assim, foi introduzida a prática pela qual, se os salários não fossem suficientes para manter o trabalhador e sua familia, seja grande ou pequena, a diferença deveria ser retirada do fundo dos pobres.

$O$ resultado disso foi o que se esperava; sendo cada filho uma fonte adicional de recursos para o trabalhador, os "positive-checks" da natureza puderam ser postos de lado, tendo se experimentado um grande aumento populacional. $O$ número de pobres cresceu alarmantemente. $O$ número de filhos não era a única razão para isso. As bem-intencionadas decisões da Justiça de que os agricultores deveriam elevar os salários quando os preços subissem, não pareceram ter sensibilizado os empregadores; muito pelo contrário, quando eles perceberam que a comunidade estaria pronta a cobrir qualquer defasagem salarial, eles viram uma oportunidade para abaixar os salários ao invés de aumentá-los. Tornou-se uma prática generalizada considerar o fundo da lei dos pobres como parte da remuneração do trabalhador. O empregador consciente tinha, então, que seguir o exemplo dos menos conscientes, ou ver seus produtos encalhados no mercado, e se o trabalhador protestasse que não podia viver com o que recebia, era-lhe dito que perderia os direitos sobre o fundo da lei dos pobres. Sobre esta regulamentação especialmente, em que as atividades não iam bem, os salários despencaram até quase desaparecerem. Em 1810, Brougham declarou no Parlamento que os salários dos tecelóes que, em 1802, eram 13 shillings e 10d. por semana, haviam caido para 4 shillings e $3 \mathrm{~d}$. dos quais, disse Brougham:

Quando as despesas usuais pagas pelos trabalhadores pelo uso da maquinária forem deduzidas, não restarão mais que 3 shillings para o sustento da vida humana por sete dias (Apud, Smart, 1949, p.59).

Foi nesse mesmo ano, 1817, que Ricardo disse ser absolutamente certo que os salários iriam subir se o preço do cereal subisse, e que seria impossivel conceber que os salários-dinheiro não alımentassem com o preço dos gêneros de primeira necessidade. Também foi nesse ano que ele introduziu o conceito de confortos moderados desfrutados pelo trabalhador, e das comodidades encontradas em uma cabana moderna. 
Um crítico posterior a Brougham disse que Ricardo legislava por Saturno (Apud Smart, 1949, p.72). Naturalmente, economistas não legislam. Eles apenas tentam, na nossa opinião, descobrir e interpretar as leis que regem a economia. $E$ foi isto que Ricardo tentou fazer ao escrever o Princípios. Ele visualizou uma comunidade onde as leis econômicas tinham liberdade de movirnento, sem interferências nem do Parlamento nem de juízes de paz. Sob o "laissez-faire", salários, lucros, preços, todos encontravam seu nivel natural:

O preço do trabalho irá expressar claramente os desejos da sociedade com relação à população. Sendo suficiente apenas para sustentar aquele contingente que o montante de fundos da manutenção do trabalho permite (Apud Sraffa, 1959, p.219).

Enquanto a competição dos trabalhadores pela participação no fundo de salários mantinha os salários baixos, a competição entre os capitalistas pela oferta de trabalho tenderia a mantê-los altos. O capital terminaria a acumulação, se os salários ameaçassem extinguir os lucros:

O agricultor e o fabricante não podem viver sem seus lucros mais do que o trabalhador sem o seu salário (Apud Sraffa, 1959, p.122).

Mas, os lucros não podem ser limitados às necessidades de subsistência dos capitalistas, pois, como comenta Brinton (1949, p.35), se os lucros forem muito baixos não haverá poupança, o capital cessará de se acumular, e a população será trazida ao estado estacionário. Se o capitalista não pode poupar nada para o auxilio de outros, então os hospitais $e$ as instituições de caridade não mais terão recursos para 0 auxílio dos desprovidos, dos idosos, dos aleijados e dos cegos. Além do mais, é sobre a renda e os lucros que a sociedade deve olhar para encontrar as possibilidades de manutenção dos trabalhadores improdutivos, o que inclui não apenas soldados e marinheiros para defender o país de agressões, e os policiais e servidores públicos para preservar a ordem e um bom governo. Ele (Ricardo) também inclui pintores, escultores, músicos, compositores, poetas, novelistas, filósofos e muitos outros cujo trabalho dá dignidade à vida e eleva o homem acima do nivel das bestas.

Tais são as condições sob o sistema de "Laissez-faire" que foi defendido por Smith, como o sistema mais eficiente na defesa do bem-estar humano sobre qualquer outro apoiado na benevolência. Podemos 
mesmo dizer que ele chegou a receber as bênçãos da lgreja, ou pelo menos as bênçãos de um reverendo, pois Malthus escreveu:

A substituição do amor próprio pela benevolência como o princípio de motivação da sociedade, em vez de produzir os melhores efeitos como era de se esperar de um nome tão benemérito, iria gerar as mesmas pressões de insatisfação em toda sociedade que agora são sentidas em apenas um de seus segmentos. É graças à propriedade privada e ao aparentemente ilimitado princípio do amor próprio, que devemos todos os nobres feitos do gênio hurnano, todas as mais sensíveis e delicadas emoções da alma, e tudo, de fato, que distingue o civilizado do selvagem (Malthus, 1933, p.280).

Ricardo subscreve este ponto de vista; tal como Malthus, ele encarava a lei dos pobres como um desvio da renda, pois o objetivo em vista nunca venceria os irremediáveis hábitos de multiplicação do trabalhador. No último parágrafo do seu capítulo sobre salários, ele escreve:

Se por lei, todo ser humano necessitado de ajuda estivesse certo de obtê-la, e em grau suficiente para tornar a vida relativamente confortável, a teoria nos levaria a esperar que todos os demais impostos fossem leves, quando comparados à taxa dos pobres. Tão verdadeiro quanto o princlipio da gravitação é a tendência de leis para transformar a riqueza e o poder em miséria e em fraqueza, para afastar os esforços do trabalho de todo objetivo, que não seja o de prover a mera subsistência, para confundir qualquer distinção quanto às faculdades intelectuais, para ocupar a mente de modo contínuo em atender às necessidades do corpo, até que, finalmente, todas as classes sejam atingidas pela praga universal (Ricardo, 1982, p.89).

\section{Ao seu amigo Trower, Ricardo escreveu:}

Estas taxas são um redemoinho onde tudo que possui valor será tragado (Apud Sraffa, 1951, p.135).

\section{E no Principios, ele escreveu:}

Nenhuma tentativa de emenda das leis dos pobres merece a menor atenção, se não tiver por objetivo final a abolição dessas leis. Aquele que mostrar como esse objetivo pode ser atingido com mais segurança e menor violência será o melhor amigo dos pobres e das causas da humanidade. Não é alterando de uma forma ou de outra o modo de obtenção do fundo para o sustento dos pobres, que se pode mitigar o mal. Não só não seria uma melhoria, como constituiria um agravamento do mal que desejamos eliminar, se o fundo se elevasse ou fosse arrecadado, como foi proposto separadamente, como uma contribuição de todo o pals (Ricardo, 1982, p.98). 
Mesmo com as miseráveis condições em que se encontrava a classe trabalhadura em 1817, como descrito por Brougham, o ponto de vista de Ricardo era de que, como

todos os demais contratos, os salários deveriam ser deixados à concorrência justa e livre, do mercado, e nunca deveriam ser controlados pela interferência da legislação (Ricardo, 1982, p.96).

Coerente com essa posição, a última atitude política no Parlamento foi votar a renovação da lei, em que os salários dos tecelões de Spitalfields eram fixados pela Magistratura num valor que Ihes dava um razoável padrão de vida (Smart, 1949, p.62).

\section{CONCLUSÃO}

Uma vez que Ricardo reconhece que muito do trabalho improdutivo é sustentado por rendas e lucros, e como ele encarava o fundo da "Lei dos Pobres" como passiveis de gerar um alarmante aumento da população, nos parece estranho que tenha deixado de lado a lei econômica que a população aumenta com o estoque de capital, ou seja, pelo fundo de salário dos capitalistas.

Faltou, portanto, a elaboração de um programa sério de controle do contingente populacional que fosse coerente com a fronteira agrícola e o ritmo de expansão do capital, sem ele o termo progresso econômico ficou paradoxalmente associado à deterioração na qualidade de vida. É verdade que Ricardo não discordava de Malthus que a castidade podia ser a palavra final aos problemas gerados pela superpopulação e os baixos salários, mas ele certamente não encarava com seriedade a possibilidade de mudanças radicais em hábitos de aceitação generalizada meramente em resposta às exortações de alguns Economistas. Sem dúvida, ele poderia ter desenvolvido uma infinidade de mecanișmos que fossem realmente eficazes nos programas de planejamento familiar, mas como inevitavelmente todos teriam que abordar um tabu delicado; sexo, talvez a única saída que Ricardo tenha encontrado para conciliar sua reputação acadêmica de liberal com os padrões de decência da época tenha sido a omissão.

\section{BIELIOGRAFIA}

BRINTON, W. The Wages Fund Controversy Revisited. Canadian Journal, 1967. 
HAROLD, Rogers. The First Industrial Nation. Cambridge, 1947.

LECKY, S. England in the Eighten Century. London. Longman, s.d.

MALTHUS, Thomas. Principles of Political Economy. Longman \& Co., 1956.

RICARDO, David. Princípios de Economia Política e Tributação. São

Paulo, Abril Cultural, 1982.

SMART, T. Economic Annals. Oxford, 1949.

SRAFFA, P. The Works and Correspondence of David Ricardo.

Cambridge, Cambridge University Press, 1951.

\section{ABSTRACT \\ RICARDO AND THE SOCIAL PROBLEMS OF HIS TIME}

In Ricardo's model, wages are determined by the subsistence level of the working class. Given that the main consumption good of the workers is corn, monetary wages depend on its price. As the demographic growth deteriorates even more the standards of living of the working classes, there was too much social tension in Ricardo's time. To him, the "Poor Law" aggravated the situation by stimulating demograhic growth. 